\title{
Protective Effect of Conventional Antioxidant ( $\beta$-Carotene, Resveratrol and Vitamin E) in Chitosan-Containing Hydrogels Against Oxidative Stress and Reversal of DNA Double Stranded Breaks Induced by Common Dental Composites: In-Vitro Model
}

\author{
V. Tamara Perchyonok ${ }^{\mathrm{a},{ }^{*}, \text { Shengmiao Zhang }}{ }^{\mathrm{b}}$ and Theunis Oberholzer ${ }^{\mathrm{c}}$ \\ ${ }^{a}$ Vtpchem Pty Ltd, Glenhuntly, Melbourne, 3163, Australia \\ ${ }^{b}$ Shanghai Key Laboratory of Advanced Polymeric Materials, Key Laboratory for Ultrafine Materials of Ministry of \\ Education, School of Materials Science and Engineering, East China University of Science and Technology, Shanghai \\ 200237, China \\ ${ }^{c}$ School of Dentistry and Oral Health, Griffith University, 4125, QLD, Australia
}

\begin{abstract}
Cytotoxic resin components of common dental bonding agents are known to cause oxidative damage and suppress odontogenic differentiation of dental pulp cells. [1-4] As antioxidants were found to protect cells from cytotoxicity of resin monomers in previous studies,[5-8] we investigated the effects of common antioxidants, such as $\beta$-carotene, resveratrol and Vitamin E on anti-differentiation activity of bonding agents without compromising bond strength.

Methacrylate monomers used in dentistry have been shown to induce DNA double strand breaks (DSBs), a severe type of DNA damage. The formation of classical products of oxidative DNA damage, were studied using the UV-detection method.

We found that exposure of 2'-deoxyguanosine, phenylalanine and 2'-deoxythymene to a commercially available dental composite restorative material (Esthet-X micromatrix restorative composite material) lead to various degrees of formation of 8-oxo-7,8-dihydro-2'-deoxyguanosine (8oxodG), tyrosine and 5-hydroxy-2'-deoxythymidine (5OHdT) as essential markers of oxidative DNA double stranded damage. The yields of 8oxodG, tyrosine and 5OHdT appear to be negligible in the presence of antioxidant containing chitosan hydrogels. We also extended the methodology to hydrogen atom transfer reactions of 2-bromo naproxen methyl ester and 2-bromoibuprofen methyl ester as important class of radical forming reactions under blue light conditions and found that Gels play an important protective role under identical conditions Gels were characterized with SEM and the images incorporated.
\end{abstract}

Conclusion: Antioxidant containing chitosan hydrogels may reduce detrimental effects induced by common composite restorative agent in vitro and introducing additional therapeutic health benefits.

Keywords: Free radicals, Oxidative damage, In vitro, Dental composites, Chitosan, Hydrogels.

\section{INTRODUCTION}

Modern dental adhesive systems are used to improve contact between restorative material and the walls of the prepared cavity of the tooth. As these materials come in close and prolonged contact with vital dentin, their influence on pulp tissue is critical. Thus, the biocompatibility of dentin bonding agents is a relevant aspect of the clinical success of these materials [1-3]. Dentin bonding agents alone proved to be cytotoxic [4], and it has been found that the type and quantity of leachable components significantly influence the biological behavior of resin restorations [5-10]. Cytotoxicity of dentin bonding agents has been examined using a variety

*Address correspondence to this author at the Vtpchem Pty Ltd, Glenhuntly, Melbourne, 3163, Australia; Tel: +(61)414596304; Fax: +(61)95725223;

E-mail: tamaraperchyonok@gmail.com of cell lines including primary human pulp and pulp-derived cells $[4,5-8,11-14]$.

As a consequence of aerobic metabolism, small amounts of reactive oxygen species (ROS) are constantly generated in cells and tissues. Cellular antioxidants like glutathione act in unison to detoxify these reactive molecules, but when the balance between oxidants and antioxidants is disrupted, a condition referred to as oxidative stress exists. If oxidative stress persists, oxidative damage to lipids, proteins and nucleic acids accumulates and eventually results in cell death [4]. Co-polymeric and monomeric form resin-based materials such as HEMA and TEGDMA are a likely cause of cellular damage via the uncontrollable generation of reactive oxygen species. Recently, the possible link between the highly reactive and poorly controlled free radical species generation and cytotoxycity has been established [15-19]. Also genotoxic effects of triethyleneglycol dimethacrylate 
Table 1. Gel Formulation Prepared in the Study

\begin{tabular}{|c|c|c|c|}
\hline Gel formulation & & Medium & $\mathbf{p H}$ \\
\hline Chitosan-H & Gel-1 & $3 \%$ acetic acid & 4.00 \\
\hline Chitosan-H+Resveratrol & Gel-2 & $3 \%$ acetic acid & 4.16 \\
\hline Chitosan-H+Vitamin E & Gel-3 & $3 \%$ acetic acid & 4.63 \\
\hline Chitosan- $\mathrm{H}+\beta$-carotene & Gel-4 & $3 \%$ acetic acid & 5.12 \\
\hline
\end{tabular}

(TEGDMA) and 2-hydroxyethylmethacrylate (HEMA) have been demonstrated in vitro as well, indicating DNA reactivity of the compounds [4, 20,21].

The human body has several mechanisms to counteract damage by free radicals and other reactive oxygen species. These act on different oxidants as well as in different cellular compartments. The presence of antioxidants is the fundamental line of defence against free radical damage. An antioxidant is a molecule stable enough to donate an electron to a reactive free radical and quench it, thus reducing its capacity to damage. Some such antioxidants, including glutathione, ubiquinol and uric acid, are produced during normal metabolism in the body. Other lighter antioxidants are found in the diet. Although about 4000 antioxidants have been identified, the best known are vitamin $\mathrm{E}$, vitamin $\mathrm{C}$ and the carotenoids. Many other non-nutrient food substances, generally phenolic or polyphenolic compounds, display antioxidant properties and, thus, may be important for health.

Although a wide variety of antioxidants in foods contribute to disease prevention, the bulk of research has focused on three antioxidants, which are essential nutrients or precursors of nutrients. These are vitamin $\mathrm{E}$, vitamin $\mathrm{C}$ and the carotenoids. Each of these antioxidant nutrients have specific activities and they often work synergistically to enhance the overall antioxidant capability of the body [15-17]. The balance between the production of free radicals and the antioxidant defences in the body has important health implications.

Chitosan, which is a biologically safe biopolymer as well as an antioxidant, has been proposed as a bioadhesive polymer and is of continuous interest to us due to its unique properties and flexibility in broad range of oral applications reported by others and us recently [15-18].

The main objective of this study was to evaluate the effect of 3 chitosan-antioxidant hydrogels on the antioxidant defence mechanism (resveratrol, vitamin $\mathrm{E}$ and $\beta$-carotene on in-vitro model of oxidative damage potentially generated by the model composite. Secondly, we aimed to investigate the chemical nature of the defence on the interface between the composites and anioxidant/chitosan hydrogel layer formation by the use of SEM.

\section{MATERIAL AND METHODS}

\section{Materials}

$\beta$-carotene (Aurora Pharmaceuticals, Australia), resveratrol (Nature's care manufacture PTY LTD, Australia), vitamin E (Now Food, Australia), 2'-deoxyguanosine (Sigma, USA), phenylalanine (Sigma, USA) and 2'-deoxycytidine (Sigma, USA) were used as received. Chitosan (Aldrich, Australia), glycerol (Sigma, USA), glacial acetic acid (E.
Merck, Germany), naproxen and ibuprofen (Sigma, USA) were used as received. The degree of deacetylation of typical commercial chitosan used in this study is $87 \%$. Chitosan with molecular weight $2.5 \times 10^{3} \mathrm{KD}$ was used in the study. Gelatin in powder form was purchased from Shanghai Chemical Reagent Co., (Shanghai, China) with the numberaverage molecular weight $(\mathrm{Mn})$ of about $8.7 \times 10^{4}$. The isoelectric point is 4.0-5.0.

Preparation of chitosan based gels with resveratrol, $\beta$ carotene or vitamin $\mathrm{E}$ as suitable bio-molecular drug delivery systems and a hybrid layer formation promoter.

Antioxidant containing chitosan gel was prepared by dispersion of corresponding antioxidant $0.2 \mathrm{gm}$ in glycerol $(5 \%$ $\mathrm{w} / \mathrm{w})$ using a mortar and a pestle. Ten milliliters of glacial acetic acid $(3 \% \mathrm{w} / \mathrm{w})$ was then added with continuous mixing and finally chitosan polymer was spread on the surface of the dispersion and mixed well to form the required gel. Antioxidant gel had been prepared with three different $2 \mathrm{w} / \mathrm{w}$ concentrations of chitosan gelling agent and the summary of the newly prepared materials is highlighted in Table 1. Glacial acetic acid was added to the preparation to obtain the homogenous clear chitosan gel.

\section{Determination of Gel pH}

One gram of the prepared gels was accurately weighed and dispersed in $10 \mathrm{ml}$ of purified water. The $\mathrm{pH}$ of the dispersions was measured using $\mathrm{pH}$ meter (HANNA instruments, HI8417, Portugal) [12].

\section{Morphology of the Gels}

The samples were prepared by freezing in liquid nitrogen for $10 \mathrm{~min}$, and then were freeze-dried for $24 \mathrm{~h}$. The prepared samples were fractured in liquid nitrogen using a razor blade. The fractured samples were attached to metal stubs, and sputter coated with gold under vacuum for SEM. The interior and the surface morphology were observed in scanning electron microscope (SEM, Hitachi S4800, Japan).

\section{$\mathrm{H}_{2} \mathrm{O}_{2} /$ Cupric Ions $\left(\mathrm{Cu}^{2+}\right)$ Hydroxyl Radical Generation in the In Vitro Conditions}

In order to further measure the reducing ability of negative control (35\% hydrogen peroxide solution and $\mathrm{CuSO}_{4}$ ), vitamin $\mathrm{C}$, vitamin $\mathrm{E}$, resveratrol and beta-carotene, the cupric ions' $\left(\mathrm{Cu}^{2+}\right)$ reducing power capacity was used with slight modification [33]. Briefly, $250 \mu \mathrm{L}$ of $37.5 \%$ hydrogen peroxide solution and $\mathrm{CuSO}_{4}$ and $250 \mu \mathrm{L} \mathrm{CH}_{3} \mathrm{COONH}_{4}$ buffer solution $(100 \mathrm{mmol} / \mathrm{L}, \mathrm{pH} 7.0)$ were added to a test vial containing a negative control $35 \%$ hydrogen peroxide solution and $\mathrm{CuSO}_{4}$ ) vitamin $\mathrm{E}$, resveratrol and $\beta$-carotene sample as well as chitosan-antioxidant gels of the vitamin E, resveratrol and $\beta$-carotene $(250 \mu \mathrm{L})$. Then, the total volume 


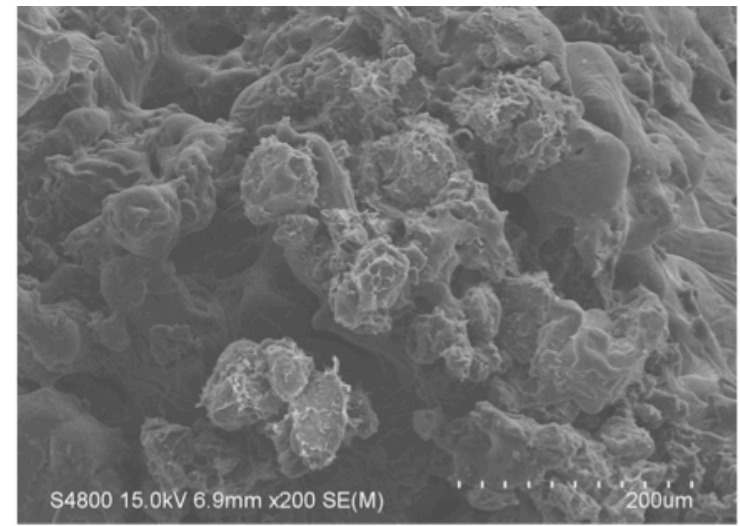

a

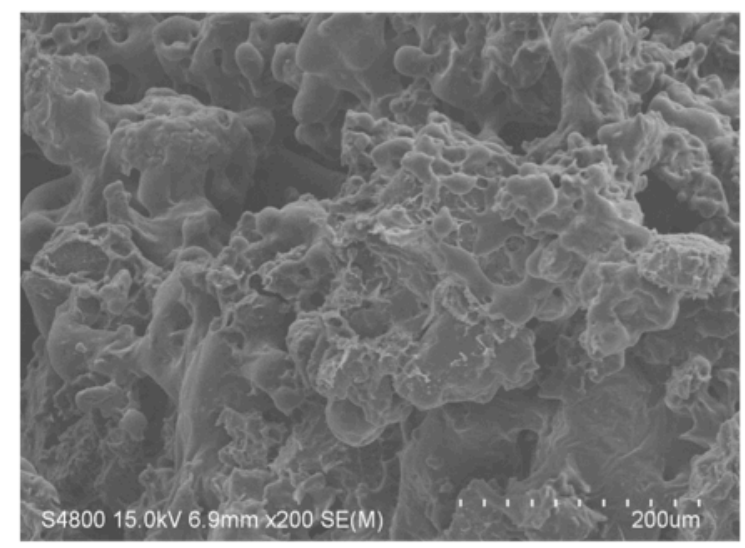

$\mathrm{C}$

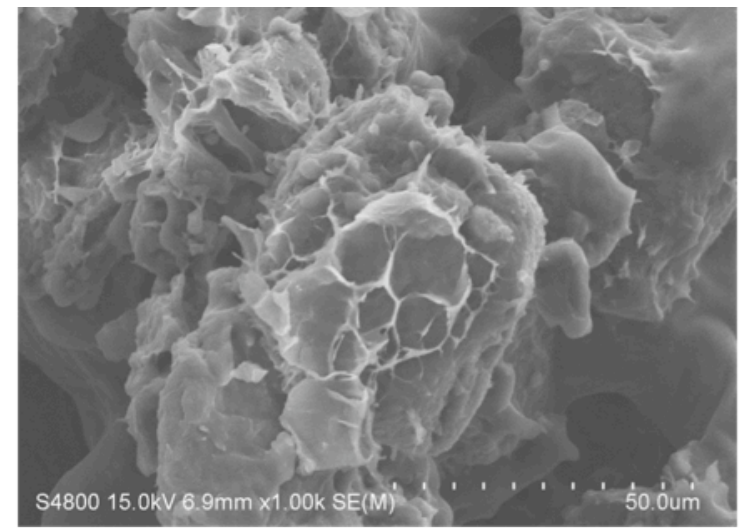

b

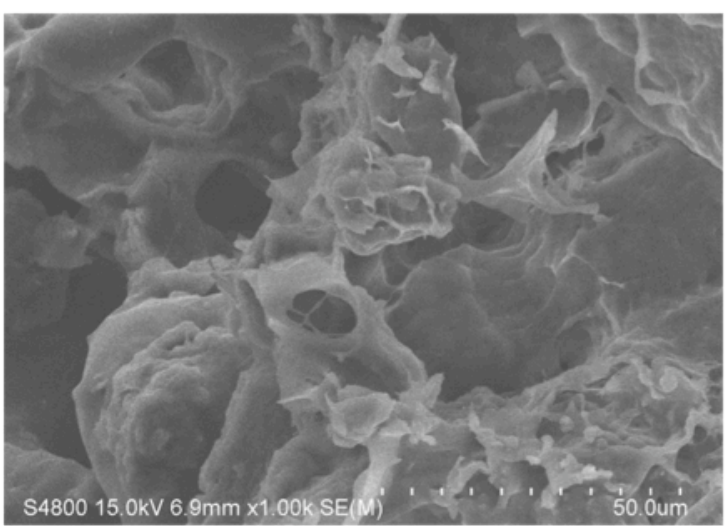

d

Fig. (1). SEM photographs of interior morphology of the selected gels under investigation for (a) Gel-1, (b) Gel-2 (c) Gel-3, (d) Gel-4.

was adjusted with the buffer to $2 \mathrm{~mL}$ and mixed vigorously. Absorbance against a buffer blank was measured at $568 \mathrm{~nm}$ at 20 minutes intervals for the total time of 2 hours. The gels were tested after 1 to 14 weeks in order to establish the longevity and the importance of stability of the gel compostion. Increased absorbance of $\mathrm{Cu}+$ complex in the reaction mixture indicates increased reduction capability. Trolox (water soluble Vitamin E) was used as a positive control. The results of the investigation are summarized in graph 2. Absorbance was measured using POLARstar Omega Multifunction Microplate Reader (BMG LABTECH, Spectral range: 220 $850 \mathrm{~nm}) .24$ well plates used in the investigations are Corning Incorporated Castar 3524, 24 well cell culture cluster flat bottom with lid, Non-pyrogenic, Polystyrene, sterile plates. (Corning Incorporated Corning, NY, 14831, USA).

\section{General Experimental Procedure for Hydrogen Atom Transfer Reaction Under Blue Light Conditions at Am- bient Temperature:}

To a solution of $\mathrm{H}_{3} \mathrm{PO}_{2}$ ( $20 \%$ solution in water, 5 equiv) and $\mathrm{Bu}_{4} \mathrm{~N}^{+} \mathrm{Cl}^{-}$(5 equiv) in water $(5 \mathrm{ml})$ was added radical precursor $(0.1 \mathrm{mmol})$ followed by irradiation with conventional composite curing light for $1 \mathrm{~h}$. The solution was stirred at room temperature for $1 \mathrm{~h}$. The reaction mixture was then extracted with EtOAc $(2 \times 10 \mathrm{ml})$ and the organic phase dried with $\mathrm{MgSO}_{4}$. The crude mixture did not require further purification and was analyzed by ${ }^{1} \mathrm{H}$, gCOSY NMR spectroscopy, and HPLCMS to confirm formation of the reduced product.

\section{RESULTS AND DISCUSSION}

Table 1 represents the summary of the additive-chitosan gels prepared and used in this study. Additive (active antioxidant) content in $0.3 \mathrm{~g}$ of different gel formulations from the prepared formulae (presented in Table 1). The prepared gel formulations have uniform distribution of drug content, homogenous texture and yellow color. The $\mathrm{pH}$ of the formulations ranged from to 4-5.12.

The SEM images were obtained to characterize the microstructure of the freeze-dried additive composite gels (gel1-4) and are presented in Fig. (1). The gels displayed a homogeneously porous structure. It was thought that the micro-porous structure of the gels could lead to high internal surface areas with low diffusional resistance in the gels. The surfaces of the gels were also presented (Fig. 1). The 'skin' of the gels can be seen, and the collapse of the surface pores may be due to the freeze-drying process.

\section{INVESTIGATION OF FREE RADICAL CHEMISTRY OF THE IN VITRO MODEL SYSTEM}

It is well established that $\mathrm{HO}$ can be generated from a reaction known as the biologic Fenton reaction, and this reaction requires the presence of $\mathrm{H}_{2} \mathrm{O}_{2}$ [22-25].

The generation of $\mathrm{HO}$ from the biologic Fenton reaction has been shown to be a critical factor in various ROSinduced oxidative stresses [24-26] $\mathrm{H}_{2} \mathrm{O}_{2}$ and $\mathrm{HO}$ might be related to apoptosis in atherosclerosis [30]. Godley et al. also 


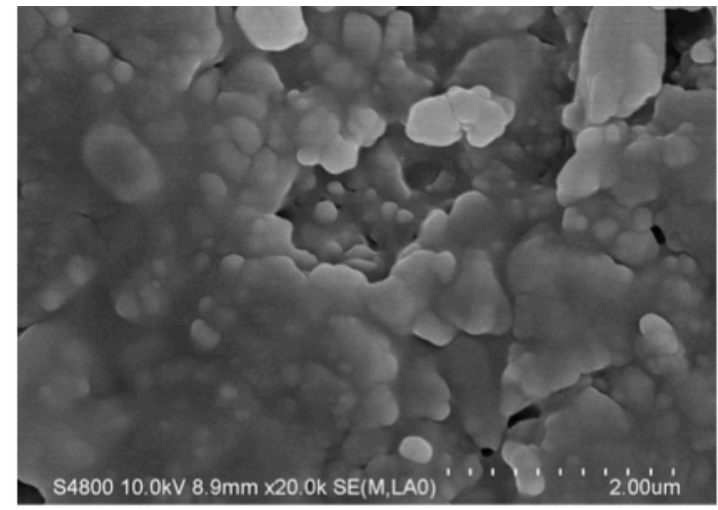

a

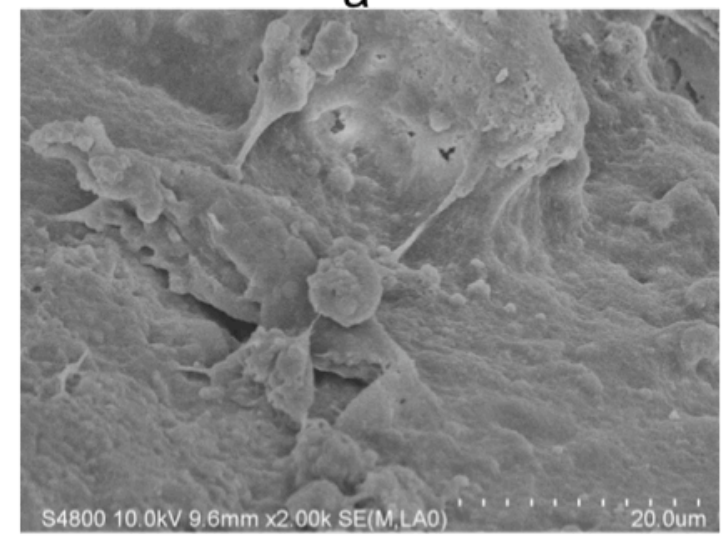

C

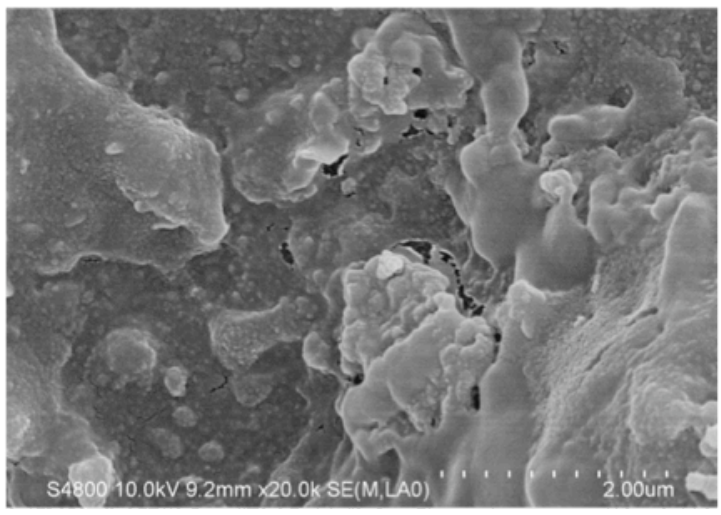

b

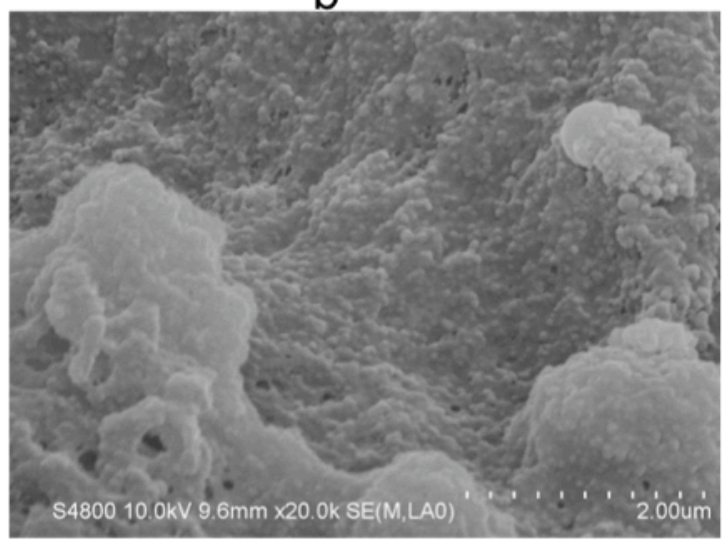

d

Fig. (2). SEM images of the reactive surface of the composite under experimental conditions: a. Gel-2 and phenylalanine, b. Gel-3 and 2deoxyguanosine, c. Gel-3 and phenylalanine, d. Gel-4 and 2'-deoxythymine.

reported that blue light induces mitochondrial DNA damage and cellular aging [31].

The reactive nature of the surface has been investigated using the SEM and comparison confirms the reactive nature of the transformation. (Fig. 2).

\section{CHEMISTRY OF REACTIVE OXYGEN SPECIES (ROS) UNDER “DENTAL CONDITIONS" IN VITRO}

Enhanced oxidative damage after diverse stimuli has been confirmed to be an initial event in the development of several important diseases and adverse reactions [32-34]. The increased and uncontrollable production of oxygen centred free species in the specific and highly vascular region will increase detrimental effects including peroxidation of membranes and eventual cell death. In contrast, the oxidative insults can be partially prevented by some free radical quenchers such as Vitamin E, flavonoids and superoxide dismutase $[35,36]$. Thus, antioxidants that react preferentially with reactive oxygen centred radicals to inactivate them might have therapeutic applications in treating free radical-induced cell damage and unnecessary cell death $[35,36]$.

Chitosan, the linear polymer of $\alpha$-glucosamine in $\beta(1,4)$ linkage, is a cellulose-like biopolymer present in the exoskeleton of crustaceans and in cell walls of fungi and insects [37]. Chitosan oligosaccharides (low-molecular weight chitosan, COS) are depolymerized products of chitosan and can be obtained by chemical and enzymatic hydrolysis of chito- san [38]. During the past decades, COS were known to have various biological activities [39-43] including its antioxidant capacity [44]. By using electron spin resonance (ESR) spintrapping technique, COS and their derivatives can show high scavenging activities on 1,1-diphenyl-2-picrylhydrazyl (DPPH), hydroxyl, superoxide and carbon-centered radicals [44-46]. Studies also showed that COS with different molecular weight (1-10 kDa) could inhibit free radical damages to murine melanoma cell line $(\mathrm{B} 16 \mathrm{~F} 1)$ in a dose-dependent manner [47]. The link between oral diseases and free radical damage requires further investigation and is one of the main objectives of this investigation.

Control experiments established the integrity of the in $v i$ tro procedures to assess intracellular ROS levels. Under unphotolized conditions or exposure of reaction mixture and peroxide and absence of $\mathrm{CuSO}_{4}$, there was virtually no fluorescence. Light exposure generated levels of ROS that were 4-5 times higher than those induced by the diamide controls, this baseline data indicates the importance of finding molecular origin of these transformations and finding alternative ways of preventing this potentially detrimental reactions from occurring (Scheme 1).

It is well established that phenolic antioxidants are useful quenchers for excessive free radical generation with a potential application in disease chemoprevention. These are subsequently of particular interest in the development of the prototype model in alternative antioxidant delivery systems 
<smiles>N[C](Cc1ccccc1)C(=O)O</smiles><smiles>CC(=O)[C@H](NC(Cc1ccccc1O)C(=O)O)C(=O)O</smiles>

no additives: $60 \%$

Gel $1 \quad 23 \%$

Gel $2 \quad 10 \%$

Gel $3 \quad 5 \%$

Gel $4 \quad 1 \%$
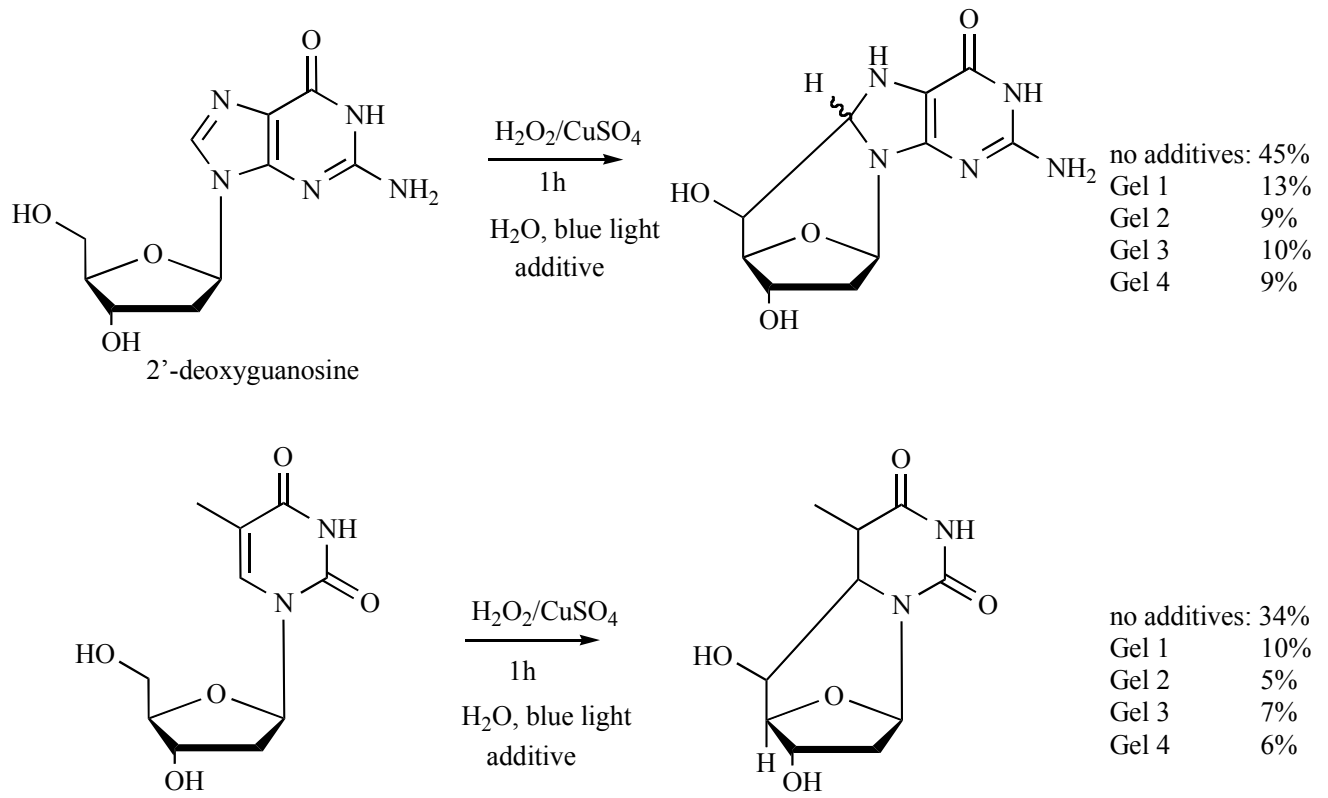

no additives: $34 \%$

Gel $1 \quad 10 \%$

Gel $25 \%$

Gel $3 \quad 7 \%$

Gel $4 \quad 6 \%$

2'-deoxythymine

Scheme 1. Reaction outcomes under Fenton conditions and potential biomarkers.

[48]. Extensive kinetic and mechanistic data exists on the formation and properties of the antioxidant, chitosan. Thus, the system is ideal for the assessment of performance of the complex in fundamental free radical transformations such as Fenton reaction and radical cascade reactions, which represent some of the key free radical transformations in vivo responsible for DNA damage, disease state and eventual cell death $[49,50]$.

Several classical free radical reaction types such as Hydrogen Atom Transfer reaction, Carbon-Carbon bond formation via free radical mediated cascade reaction and free radical hydroxylation were investigated in artificial saliva using $\mathrm{H}_{2} \mathrm{O}_{2} / \mathrm{Cu}^{2+}$ and hypophosphorous acid/surfactant $\left(\mathrm{H}_{3} \mathrm{PO}_{2} / \mathrm{Bu}_{4} \mathrm{NBr}\right)$ in water and as trial reactions probing the extent of oxidative stress and free radical damage (Scheme 2). Typical free radical precursors such as tertiary bromides of protected commonly used NSADs such as naproxen and ibuprofen were used in hydrogen atom transfer reactions. Racemic phenylalanine, 2-deoxythymine and 2deoxyguanosine were used as typical precursors for the Fenton reactions. All reaction mixtures were analyzed using HPLC/MS and mixtures were further purified using conventional chromatographic techniques. For comparison purposes, reactions were conducted in the aqueous media with no inhibitor, chitosan Gel 1 and corresponding antioxidant under previously determined conditions for optimal generation of free radical transformation. Reactions in the presence of chitosan, antioxidant or chitosan: antioxidant gel demonstrated significant inhibition of the undesirable reaction outcome and effectiveness of the proposed methodology.

\section{CONCLUSION}

We have demonstrated the application of two effective molecular prototype delivery systems able to harness free radical reactivity within the laboratory where biological processes can be studied and controlled, in an attempt to translate the in vitro research for the development of new preventative measures for disease states mediated by free radicals.

Further studies are needed to elucidate more precisely the mechanisms of biological damage from oxidative stress and the mechanisms for defense of the dental pulp when using a wide variety of free radical generation procedures such as bleaching, blue light irradiation and LED light source commonly employed in dentistry. The positive influence of gels, containing chitosan/antioxidant in the hydrogen transfer transformations broadens the potential application of the 


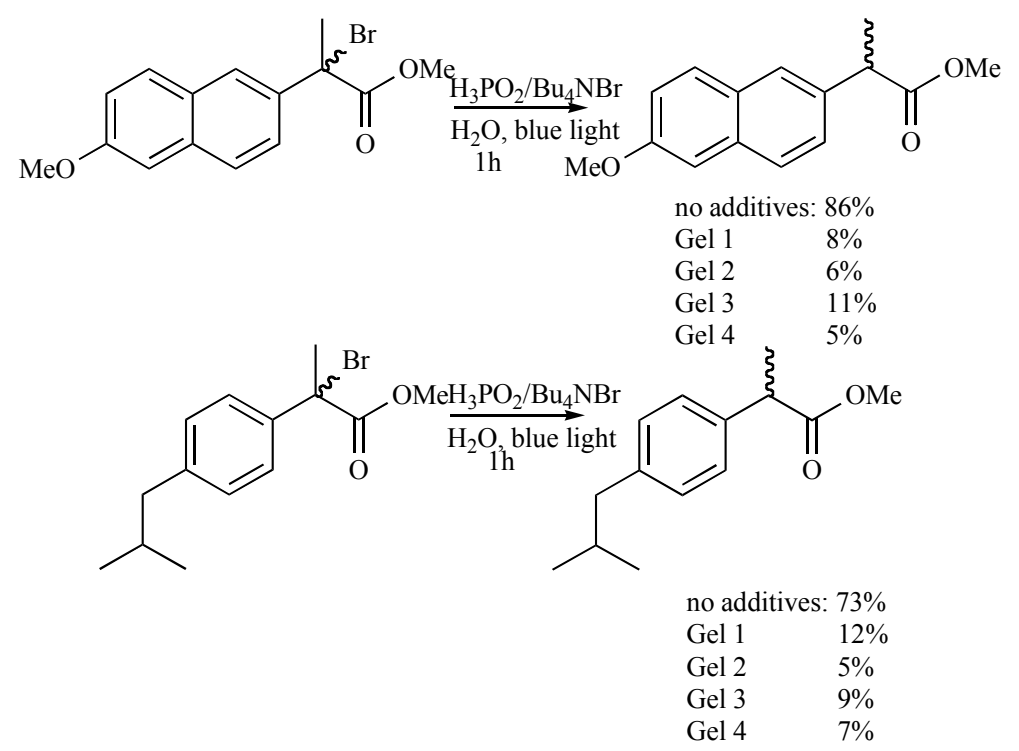

Scheme 2. Reaction outcomes under Hydrogen Atom transfer conditions and potential pro-drug prototypes.

methodology for controlling free radical damage in the oral environment.

\section{CONFLICT OF INTEREST}

The authors confirm that this article content has no conflicts of interest.

\section{ACKNOWLEDGEMENT}

Declared none.

\section{REFERENCES}

[1] Sandler, J.S.; Colin, P.L.; Kelly, M.; Fenical, W. Sterol mutants of Saccharomyces cerevisiae: chromatographic analyses. J. Org. Chem., 2006, 71, 8684 .

[2] Schmalz, G. Concepts in biocompatibility testing of dental restorative materials. Clin. Oral Invest., 1997, $1,154$.

[3] Peumans, M.; Kanumilli, P.; De-Munck, J.; Van Landuyt, K.; Lambrechts, P.; Van Meerbeek, B. Clinical effectiveness of contemporary adhesives: a systematic review of current clinical trials. Dent. Mater., 2005, 21, 864

[4] Murray, P.E.; Windsor, L.J.; Hafez, A.A.; Stevenson, R.G.; Cox, C.F.; Comparison of pulp responses to resin composites. Oper. Dent., 2003, 28, 242.

[5] Olivier, A.; Grobler, S.R.; Osman, Y. Cytotoxicity of seven recent dentine bonding agents on mouse 3 T3 fibroblast cells. Open $J$. Stomatol., 2012, 2, 244.

[6] Chen, R.S.; Liu, C.C.; Tseng, W.Y.; Jeng, J.H.; Lin, C.P.; Cytotoxicity of three dentin bonding agents on human dental pulp cells. $J$. Dent., 2003, 31, 223.

[7] Chen, R.S.; Liuiw, C.C.; Tseng, W.Y.; Hong, C.Y.; Hsieh, C.C.; Jeng, J.H. The effect of curing light intensity on the cytotoxicity of a dentin-bonding agent. Oper. Dent., 2001, 26, 505.

[8] de Souza Costa, C.A.; Vaerten. M.A.; Edwards, C.A.; Hanks. C.T. Cytotoxic effects of current dental adhesive systems on immortalized odontoblast cell line MDPC-23. Dent. Mater., 1999, 15, 434.

[9] Vajrabhaya, L.O.; Pasasuk, A., Harnirattisai, C., Cytotoxicity evaluation of single component dentin bonding agents. Oper. Dent., 2003, 28, 440 .

[10] Szep, S.; Kunke, 1.A.; Ronge, K.; Heidemann, D. Cytotoxicity of modern dentin adhesives - in vitro testing on gingival fibroblasts. J. Biomed. Mater. Res., 2002, 63, 53.

[11] Geurtsen, W.; Spahl, W.; Muller, K.; Leyhausen, G. Aqueous extracts from dentin adhesives contain cytotoxic chemicals. J. Biomed. Mater. Res., 1999, 48, 772.
[12] Koliniotou-Koubia, E.; Dionysopoulos. P.; Koulaouzidou, E.A.; Kortsaris. A.H.; Papadogiannis, Y. In vitro cytotoxicity of six dentin bonding agents. J. Oral. Rehabil., 2001, 28, 971.

[13] Kaga, M.; Noda, M.; Ferracane, J.L.; Nakamura, W.; Oguchi, H. Sano, H.; The in vitro cytotoxicity of eluates from dentin bonding resins and their effect on tyrosine phosphorylation of L929 cells. Dent. Mater., 2001, 17, 333.

[14] Mantellini, M.G.; Botero, T.M.; Yaman, P.; Dennison, J.B.; Hanks, C.T. Adhesive resin induces apoptosis and cell-cycle arrest of pulp cells. J. Dent. Res., 2003, 82, 592.

[15] About, I.; Camps, J.; Burger, A.S.; Mitsiadis, T.A.; Butler, W.T.; Franquin, J.C. Polymerized bonding agents and differentiation in vitro of human pulp cells into odontoblast-like cells. Dent. Mater, $\mathbf{2 0 0 5}, 21,156$.

[16] Thonemann, B.; Schmalz, G. Immortalization of bovine dental papilla cells with simian virus 40 large t-antigen. Arch. Oral. Biol., 2000, $45,857$.

[17] Thonemann, B.; Schmalz, G. Bovine dental papilla-derived cells immortalized with HPV 18 E6/E7. Eur. J. Oral. Sci., 2000, 108 , 432.

[18] Galler, K.M.; Schweikl, H.; Thonemann, B.; D’Souza, R.N.; Schmalz, G. Human pulp-derived cells immortalized with Simian Virus 40 T-antigen. Eur. J. Oral Sci., 2006,114, 138.

[19] Schmalz, G.; Schuster, U.; Nuetzel, K.; Schweikl, H. An in vitro pulp chamber with three-dimensional cell cultures. J. Endodont., 1999, 25, 24-9.

[20] Schuster, U.; Schmalz, G.; Thonemann, B.; Mendel, N.; Metzl, C. Cytotoxicity testing with three-dimensional cultures of transfected pulp-derived cells. J. Endodont., 2001; 27: 259-65.

[21] Spagnuolo, G.; Annunziata, M.; Rengo, S. Cytotoxicity and oxidative stress caused by dental adhesive systems cured with halogen and LED lights. Clin. Oral Invest., 2004, 8, 81.

[22] Atsumi, T.; Iwakura, I.; Fujisawa, S.; Ueha, T. The production of reactive oxygen species by irradiated camphorquinone-related photosensitizers and their effect on cytotoxicity. Arch. Oral Biol., 2001, 46, 391.

[23] Spagnuolo, G.; D’Anto, V.; Cosentino, C.; Schmalz, G.; Schweikl, $\mathrm{H}$.; Rengo, S. Effect of $\mathrm{N}$-acetyl-1-cysteine on ROS production and cell death caused by HEMA in human primary gingival fibroblasts. Biomaterials, 2006, 27, 1803.

[24] Janke, V.; von-Neuhoff, N.; Schlegelberger, B.; Leyhausen, G.; Geurtsen, W. TEGDMA causes apoptosis in primary human gingival fibroblasts. J. Dent. Res., 2003, 82, 814.

[25] Schweikl, H.; Hartmann, A.; Hiller, K.A.; Spagnuolo, G.; Bolay, C.; Brockhoff, G. Inhibition of TEGDMA and HEMA-induced genotoxicity and cell cycle arrest by $\mathrm{N}$-acetylcysteine. Dent. $\mathrm{Ma}$ ter., 2007, 23(6), 688 .

[26] Godley, B.F.; Shamsi, F.A.; Liang, F.Q.; Jarrett, S.G.; Davies, S.; Boulton, M. Blue light induces mitochondrial DNA damage and 
free radical production in epithelial cells. J. Biol. Chem., 2005, 280, 21066.

[27] Jones, C.A.; Huberman, E.; Cunningham, M.L.; Peak, M.J.; Mutagenesis and cytotoxicity in human epithelial cells by far- and near-ultraviolet radiations: action spectra. Radiat. Res., 1987, 110, 244.

[28] Peak, J.G.; Peak, M.J. Comparison of initial yields of DNA-toprotein crosslinks and single-strand breaks induced in cultured human cells by far- and nearultraviolet light, blue light and X-rays. Mutat. Res., 1991, 246,187.

[29] Peak, J.G.; Peak, M.J. Induction of slowly developing alkali-labile sites in human P3 cell DNA by UVA and blue- and green-light photons: action spectrum. Photochem. Photobiol., 1995, 61, 484.

[30] Peak, J.G.; Peak, M.J.; Sikorski, R.S.; Jones, C. A. Induction of DNA-protein crosslinks in human cells by ultraviolet and visible radiations: action spectrum. Photochem. Photobiol., 1985, 41, 295.

[31] Noell, W. K.; Walker, V. S.; Kang, B. S.; Berman, S. Retinal damage by light in rats. Invest. Ophthalmol., 1996, 5, 450.

[32] Setlow, R.B.; Grist, E.; Thompson, K.; Woodhead, A.D. Wavelengths effective in induction of malignant melanoma. Proc. Natl. Acad. Sci. USA., 1993, 90, 6666.

[33] Setlow, R.B.; Woodhead, A.D. Temporal changes in the incidence of malignant melanoma: explanation from action spectra. Mutat. Res., 1994, 307, 365-74.

[34] Tyrrell, R.M.; P. Werfelli, P.; Moraes, E.C. Lethal action of ultraviolet and visible (blue-violet) radiations at defined wavelengths on human lymphoblastoid cells: action spectra and interaction sites. Photochem. Photobiol., 1984, 39, 183

[35] Yoshida, A.; Yoshino, F.; Tsubata, M.; Ikeguchi, M.; Nakamura, T.; Lee, M. C. Direct assessment by electron spin resonance spectroscopy of the antioxidant effects of French maritime pine bark extract in the maxillofacial region of hairless mice. J. Clin. Biochem. Nutr., 2011, 49, 79.

[36] Winkler, B.S.; Boulton, M.E.; Gottsch, J.D.; Sternberg, P. Oxidative damage and age-related macular degeneration. Mol. Vis., 1999, 5,32 .

[37] Caughman, W.F.; Rueggeberg, F.A.; Curtis Jr. J.W.; Clinical guidelines for photocuring restorative resins. J. Am. Dent. Assoc., $\mathbf{1 9 9 5}, 126,1280$.
[38] Marson, F.; Sensi, L.; Vieira, L.; Araújo, E. Clinical evaluation of in-office dental bleaching treatments with and without the use of light-activation sources, Oper. Dent., 2008, 33, 15.

[39] Luk, K.; Tam, K.; Hubert, M. Effect of light energy on peroxide tooth bleaching. J. Am. Dent. Assoc., 2004, 135, 194.

[40] Nomoto, R.; McCabe, J.F.; Hirano, S. Comparison of halogen, plasma and LED curing units. Oper. Dent., 2004, 29, 28.

[41] Ohira, A.; Ueda, T.; Ohishi, K.; Hiramitsu, T.; Akeo, K.; Obara, Y. Oxidative stress in ocular disease. Nihon Ganka Gakkai Zasshi., 2008,112, 22.

[42] Byers, M.R. Dental sensory receptors. Int. Rev. Neurobiol., 1984 25,39 .

[43] Walker, J.W.; Martin, H.; Schmitt, F.R.; Barsotti, R.J. Rapid release of an alpha-adrenergic receptor ligand from photolabile analogues. Biochemistry., 1993, 32, 1338.

[44] Hockberger, P.E.; Skimina, T.A.; Centonze, V.E.; Lavin, C.; Chu, S.; Dadras, S.; Reddy, J.K.; White, J.G. Activation of flavincontaining oxidases underlies lightinduced production of $\mathrm{H}_{2} \mathrm{O}_{2}$ in mammalian cells. Proc. Natl. Acad. Sci. USA., 1996, 96, 6255.

[45] Peak, M.J.; Peak, J.G. Solar-ultraviolet-induced damage to DNA Photodermatol., 1989, 6, 1 .

[46] Specht, S.; Leffak, M.; Darrow, R.M.; Organisciak, D.T. Damage to rat retinal DNA induced in vivo by visible light. Photochem. Photobiol., 1999, 69, 91 .

[47] Cunningham, M.L.; Krinsky, N.I.; Giovanazzi, S.M., Peak, M.J. Superoxide anion is generated from cellular metabolites by solar radiation and its components. J. Free Radic. Biol. Med., 1985, 1, 381.

[48] Peak, M.J.; Peak, J.G. Hydroxyl radical quenching agents protect against DNA breakage caused by both $365-\mathrm{nm}$ UVA and by gamma radiation. Photochem. Photobiol., 1990, 51, 649.

[49] Bartold, P.M.; Wiebkin, O.W.; Thonard, J.C.; The effect of oxygen-derived free radicals on gingival proteoglycans and hyaluronic acid. J. Periodontal. Res., 1984, 19, 390.

[50] Chapple, I.L. Role of free radicals and antioxidants in the pathogenesis of the inflammatory periodontal diseases. Clin. Mol. Pathol., 1996, 49, M247-55,

(C) Perchyonok et al.; Licensee Bentham Open.

This is an open access article licensed under the terms of the Creative Commons Attribution Non-Commercial License (http://creativecommons.org/licenses/by-nc/3.0/) which permits unrestricted, non-commercial use, distribution and reproduction in any medium, provided the work is properly cited. 